\title{
Development and Preliminary Evaluation of a System to Rapidly Measure Coefficient of Friction on Soft Contact Lenses
}

\author{
Daniel Joseph Hook ${ }^{1, *}$, Charles Phillip Lusignan ${ }^{1,2}$, Katarzyna Aneta Wygladacz ${ }^{1}$, \\ Jeffery Merrill Schafer ${ }^{1}$, Robert Brian Steffen ${ }^{1}$, William Thomas Reindel ${ }^{1}$, \\ Gary Michael Mosehauer ${ }^{1}$ \\ ${ }^{1}$ Bausch \& Lomb Incorporated, Rochester, USA \\ ${ }^{2}$ Department of Physics and Astronomy, Rochester Institute of Technology, Rochester, USA
}

Email address:

Daniel.Hook@bausch.com(D. J.Hook),cplsps@rit.edu(C.P. Lusignan),Katarzyna.Wygladacz@bausch.com(K. A. Wygladacz), Jeffery.Schafer@bausch.com (J.M. Schafer), Robert.Steffen@bausch.com(R. B. Steffen), Bill.Reinde1@bausch.com (W.T.Reindel), Gary.Mosehauer@bausch.com(G. Mosehauer)

${ }^{*}$ Corresponding author

\section{To cite this article:}

Daniel Joseph Hook, Charles Phillip Lusignan, Katarzyna Aneta Wygladacz, Jeffery Merrill Schafer, Robert Brian Steffen, William Thomas Reindel, Gary Michael Mosehauer. Development and Preliminary Evaluation of a System to Rapidly Measure Coefficient of Friction on Soft Contact Lenses. International Journal of Ophthalmology \& Visual Science. Vol. 4, No. 4, 2019, pp. 88-96. doi: 10.11648/j.ijovs.20190404.16

Received: October 2, 2019; Accepted: October 22, 2019; Published: November 14, 2019

\begin{abstract}
This study was undertaken to 1. develop an apparatus to rapidly measure coefficient of friction (COF) on soft contact lenses; 2. determine if COFs measured on two daily-disposable lens models before and after wear are consistent with changes in lens surface morphology observed in parallel atomic force microscopy (AFM) images. Methods: A stress rheometer was adapted to measure COF on a soft contact lens by custom fabrication of a rapid-mount sample stage for increased throughput. Five subjects were randomly assigned to wear daily disposable nesofilcon A and delefilcon A contact lenses bilaterally for 4 hours, after which time lenses were removed. Static and kinetic COFs of lenses worn on left eyes was measured, while lenses worn on right eyes were imaged in parallel by AFM in tapping mode. Root mean square (RMS) surface roughness was calculated for all lenses to determine the effect of wear on surface topography. Results: Both static and kinetic COFs measured on unworn delefilcon A silicone hydrogel lenses were greater than on nesofilcon A traditional hydrogel lenses. Static COF on nesofilcon A increased significantly after wear, while kinetic COF trended higher but did not change significantly. Similarly, static COF on delefilcon A also increased significantly after wear, and kinetic COF trended higher but did not change significantly, both remaining greater than on worn nesofilcon A. Parallel AFM analysis demonstrated that nesofilcon A lenses are smoother than are delefilcon A out of the package. Both lenses attracted deposits during wear, but the nesofilcon A surface was less altered by on-eye wear than was the delefilcon A surface. Conclusion: A system to rapidly measure static and kinetic COFs was successfully developed. Static and kinetic COFs measured on delefilcon A were greater than on nesofilcon A lenses. More deposits and greater surface roughness were observed after wear on delefilcon A relative to nesofilcon A. Parallel AFM images of worn and unworn lenses were not predictive of measured COFs, but increased roughness visible by AFM was consistent with observed increases in COF, although not all increases were statistically significant.
\end{abstract}

Keywords: Daily Disposable Contact Lens, Atomic Force Microscopy, Coefficient of Friction, Tribological Measurement Technique 


\section{Introduction}

Tribological analytical techniques are useful for characterizing micromechanical interactions between a material and a rubbing surface (countersurface). Interactions between the ocular surface, the tear film, the eyelid, and the lens are complicated and not completely understood. The coefficient of friction (COF) quantifies the relative resistance to motion between the lens and another surface, and is important since $\mathrm{COF}$ is reported to correlate with subjective comfort of the lens wearer [1-3].

$\mathrm{COF}$ is sometimes mistakenly described as a lens material property, but should properly be described as a system property (i.e., dependent upon contact equipment and method, lens polymer, test fluid, rubbing surface, etc.) [1]. Test systems reported in literature are generally custom built and not standardized; these include pad-on-disk [4], sphereon-lens [5], plate-on-lens [6], and disk-on-lens [1], among others. Fixturing, rub surface, rubbing speed, contact area, and applied normal force vary significantly between investigators. Indeed, poly (methylmethacrylate) (PMMA) and poly (2-hydroxyethyl methacrylate) (PHEMA) [4], glass $[1,5]$, mucin-coated glass [6], and epithelium [7] are among the rub surfaces reported. Such exotic rub surfaces add even more complexity to the measurement. COF can be measured dry or in the presence of a lubricating fluid, which also is not standardized. Buffered saline [8], ophthalmic solutions [4], cell growth media [7], protein solutions [8], and artificial tear fluid [1] have all been reported. A clear understanding of the factors governing the COF response has not been well documented, even in the simplest cases. More exotic surfaces and test fluids may be more indicative of the physiological system of the eye, but the added complexity has only made interpretation and comparison of COF results more difficult.

Test parameters that impact measured COF values include the composition, surface roughness, and geometry of the rub tool, the lubricating fluid [9], the applied normal and axial forces, and the rub speed [10]. Lipids and proteins deposited from lubrication fluid on the lens also affect COF. (COF measured on a worn lens is typically higher than that on the unworn lens, but this depends upon the character of the lens and the lens deposits.) Thus, it is preferable to choose a system (rub tool, geometry, lubricating fluid, speed, forces, etc.) and vary only the contact lens to understand the general trends of the lenses evaluated. Many systems measure COF quickly once the measurement begins but require cumbersome, time-consuming lens mounting.

Atomic Force Microscopy (AFM) is an analytical technique useful for imaging and characterizing contact lens surfaces and lens deposits [11]. However, definitive identification of species present within a deposit requires complementary analyses using other analytical techniques. The AFM technique can be readily used to image the lens polymer, as well as lipid/protein present on the lens after wear [12], or after in vitro incubation with artificial tear solution [13]. Lens polymers are often imaged by AFM in tapping mode, in which a cantilever tip oscillates at its natural resonance frequency and repeatedly contacts the surface for short increments of time as the cantilever is rastered over the analysis area. Toca-Herrera describes the technique in detail [14]. Briefly, the vibrating tip repeatedly nears, taps, and retreats from the surface, which changes the amplitude of vibration dependent upon surface topography. In tapping mode, the tip passes over surface peaks and valleys, which decrease and increase vibration amplitude, respectively. Changes are measured optically and relayed to a feedback controller that corrects the oscillation amplitude before the next tap. Compiled data are used to generate 2D projections and 3D representations of surface topography.

AFM can also be used to image areas of the surface that interact differently with the tip based upon differences in adhesion, friction, chemical, physical, or mechanical properties. In phase mode, a cantilever oscillation phase shift occurs dependent upon interaction of the tip with the surface $[15,16]$. Compiled phase shift data allow generation of $2 \mathrm{D}$ projections of different surface species. The technique can be used to distinguish areas of a contact lens that differ in physical and/or chemical properties, as well as lens deposits adherent to the lens. When the 2D phase image is projected onto the 3D topographic image, a 3D representation of surface deposits results.

The objectives of this study were two-fold, first to develop a user-friendly apparatus to rapidly measure COF on soft contact lenses with rapid lens mounting, and second to determine if $\mathrm{COF}$ measured on two daily-disposable lens models under standardized test conditions before and after wear are consistent with changes in surface topology as imaged by AFM.

\section{Material and Methods}

\subsection{Contact Lenses}

Two daily disposable (DD) contact lenses with high surface water content, Biotrue ONEday (nesofilcon A, Bausch \& Lomb Incorporated, Rochester NY) [17] and Dailies Totall (delefilcon A, Alcon, Ft. Worth TX) [18] were recently developed to improve wearing outcomes. Nesofilcon A is an FDA Group II (high-water, non-ionic, traditional hydrogel) [19] 78\% water lens material with a high concentration of polyvinylpyrrolidone (PVP), as well as amphiphilic poloxamer 407 (Pluronic ${ }^{\circledR}$ F127, BASF, Florham Park, NJ, USA) incorporated into the lens (Table 1). In contrast, delefilcon A is an FDA Group V-Cm (low-water, non-ionic, surface-treated, silicone hydrogel), 33\% bulk water lens material with $\geq 80 \%$ surface water, which is achieved by reaction of the lens surface with polyamidoamine and poly (acrylamide-acrylic acid) wetting agents [20]. Based upon AFM images of the hydrated delefilcon A lens, the hydrophilic surface layer extends $6 \mu \mathrm{m}$ beyond the hydrophobic silicone hydrogel core [21]. As nesofilcon A is a traditional hydrogel and delefilcon A a silicone hydrogel with a traditional hydrogel-like surface, the lenses are more similar to each other with respect to surface character than would be expected compared with other silicone hydrogel lenses. 


\subsection{Test Subjects}

Five subjects were recruited and consented to participate in this study. Each wore delefilcon A and nesofilcon A contact lenses bilaterally for 4 hours, in randomized order. Lenses were removed, and COFs were measured on those worn in left eyes, while those worn in right eyes were imaged by AFM.

Table 1. Contact Lenses Evaluated.

\begin{tabular}{lllll}
\hline Material & Water Content & FDA Group & Brand Name & Manufacturer \\
\hline nesofilcon A & $78 \%$ & II (High-water, Non-ionic) & Biotrue ONEday & $\begin{array}{l}\text { Bausch \& Lomb Incorporated } \\
\text { (Rochester, NY) }\end{array}$ \\
delefilcon A & $33 \%$ bulk, $>80 \%$ surface & $\begin{array}{l}\text { V-Cm (Low-water, Non-ionic, Surface- } \\
\text { treated, Silicone Hydrogel) }\end{array}$ & Dailies Total 1 & $\begin{array}{l}\text { Alcon Laboratories, Inc } \\
\text { (Ft. Worth, TX) }\end{array}$ \\
\hline
\end{tabular}

\subsection{Coefficient of Friction Measurement Apparatus and Method}

Our goal was to develop a robust analytical test method that captures many important features of the lens-on-eye system, but that also shows how the choice of lens material or immersion fluid impacts the friction response. Our approach is relevant for systematically exploring how lipid and protein deposits change the friction response for a given lens material.

Friction is a system property that depends upon the two surfaces in contact and the force pressing them together, as well as the fluid located between the surfaces. Our approach captures the most important features of in situ lens wear while simultaneously maintaining measurement simplicity. Static and kinetic COF measurements were obtained on both control lenses and worn lenses using a DHR3 controlled stress rheometer (TA Instruments, New Castle, DE) outfitted with custom tooling designed to hold and rub an immersed contact lens, (Figure 1). We selected the DHR3 because of its superior torque, axial force, position, and rotation speed specifications.
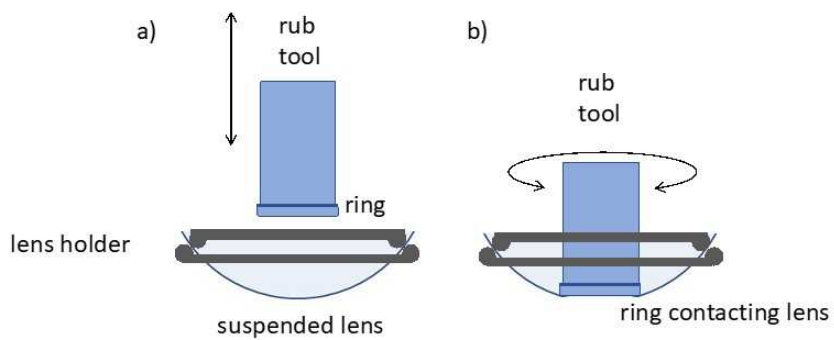

Figure 1. Schematic of lens and rub tool.

The friction perceived by a person wearing a contact lens is due to both the lens rubbing against the cornea and the eyelid rubbing against the lens. The force pressing the lens against the cornea or the lid against the lens may be inferred from the eyelid pressure against the native eye. It is reported to be in the range of 0.5 to $2 \mathrm{kPa}$ [22]. Multiple rubbing speeds occur over the blink cycle, i.e., slower motion of the lens on the cornea after completion of a blink and faster motion of the lens during a blink. Both static and kinetic friction responses occur during wear. On-eye, the lens is immersed in tear fluid, which is primarily saltwater. The impact of other materials in tear fluid is complicated, and can best be studied by wearing lenses and then measuring them in our test configuration since the major impact of tears is to foul the lens surface during wear. The on-eye temperature of interest is approximately $35^{\circ} \mathrm{C}$, but preliminary experiments found no dependence of our results upon temperature; thus, we standardized temperature to $25^{\circ} \mathrm{C}$ to improve experimental repeatability and throughput.

In any friction experiment, the choice of rubbing surface is critical. It must be consistent and unchanging to insure repeatable measurements, and to facilitate objective comparisons between different lens materials. The rub surface must also be readily cleaned to achieve high throughput. Most importantly, to be indicative of on-eye response, it must have a surface roughness less than the roughness of the hydrated tissues in the eye, which is reported to be approximately 100 to $200 \mathrm{~nm}$ [23].

We chose to fabricate our rub surface from \#316 stainless steel since it could be machined and electropolished into a durable tool with a 50 to $60 \mathrm{~nm}$ average surface roughness. The steel tools may be easily cleaned with a toothbrush using aqueous citric acid and isopropyl alcohol. Since the lens is a viscoelastic hydrogel, it readily conforms to the steel tools used in our experiment.

To yield a stress similar to eyelid pressure in our geometry, an axial force in the range of 0.02 to $0.05 \mathrm{~N}$ is required. Since contact lenses are viscoelastic materials, this is achieved during loading by allowing the stress to relax every time the axial force is varied. Typically, a constant axial force was achieved within 2 to $3 \mathrm{~min}$.

We built custom tooling for the DHR3 to hold and rub an immersed contact lens at constant temperature. In our experiment, the rheometer rubs the polished steel 'ring' surface against a suspended contact lens in rotation at a force corresponding to eyelid pressure as shown schematically in Figure 1. To make physiologically meaningful friction measurements, the rub tool must exert a pressure on the lens similar to that encountered on eye (about $2 \mathrm{kPa}$ ), a point sometimes overlooked in the literature.

We chose Borate Buffered Saline (BBS) with a $\mathrm{pH}$ of 7.2 $(0.010 \mathrm{~g} / \mathrm{ml}$ boric acid, $0.004 \mathrm{~g} / \mathrm{ml}$ sodium chloride, 0.001 $\mathrm{g} / \mathrm{ml}$ sodium borate) as the test fluid, since it is commonly used as the base fluid in many contact lens products, e.g., packaging solution, lens multipurpose solution (MPS), rewetting drops.

The geometry of the rubbing surface was chosen to be a " 6 
$\mathrm{mm}$ diameter ring" (essentially half of a torus with ID $=4.98$ $\mathrm{mm}, \mathrm{OD}=6.50 \mathrm{~mm}$, and cross-sectional radius $=0.38 \mathrm{~mm}$ ). When loaded in the test geometry with an applied axial force, the contact lens wraps around the ring slightly, so our effective contact diameter where the steel touches the lens is $6.00 \mathrm{~mm}$. Our friction experiments exploit the rotational motion of the rheometer by sliding the steel over the lens through multiple revolutions and facilitating signal averaging. The well-defined contact area of the ring-lens geometry makes conversion of the applied torque to the applied friction force straightforward.

Friction is characterized by a numerical coefficient, the COF, which is defined as the ratio of the measured tangential force $F_{T}$ to move the steel rub tool at a constant speed $v$ divided by the applied normal force $F_{N}$ pressing the surfaces together. The tangential force is calculated from the applied torque $\tau$ divided by the lever arm $R$ (the effective radius of the steel ring rub tool). $\mathrm{COF}$ at the desired speed is then calculated as:

$$
\text { CoF }=\frac{F_{T}}{F_{N}}=\frac{\tau}{R F_{N}}
$$

To obtain the static coefficient of friction, the torque $\tau$ was ramped at $2 \mu \mathrm{N} \cdot \mathrm{m} / \mathrm{s}$ from 0 to $500 \mu \mathrm{N} \cdot \mathrm{m}$ while the rub tool velocity $v$ was monitored. The torque increased the friction between the lens and the rotating tool, which applied a force that deformed the lens in a twisting motion. Eventually the rub tool broke free from the lens surface and began to spin. The force at which this occurred was recorded to determine static COF. The probe was then rotated at a constant 'low' speed of $0.25 \mathrm{rad} / \mathrm{s}(0.075 \mathrm{~cm} / \mathrm{s}$ linear speed at the ring radius of $3 \mathrm{~mm}$ ) and the force recorded and averaged for 2 min to calculate kinetic COF. Five sample loadings were performed for both static and kinetic COF determinations. Measurements at faster speeds are possible, and will be the subject of a future report.

\subsection{Atomic Force Microscopy (AFM) Imaging and Surface Roughness Measurement}

A Dimension ICON Atomic Force Microscope (Bruker, Billerica, MA) was used to characterize control contact lens surfaces and worn lenses. Unworn lenses were removed from their blister packages and rinsed overnight in HPLC grade water to remove residual packaging solution; worn lenses were removed from the right eye, assembled on custom-made holders, and immediately characterized by AFM. Images were captured using etched Si AFM probes (Bruker) and soft tapping mode. Tuning of the tips was done automatically through instrument software (NanoScope version 8.15). Both topographic [14] and phase [24] images of $40 \mu \mathrm{m} \times 40 \mu \mathrm{m}\left(1600 \mu \mathrm{m}^{2}\right)$ scan areas were recorded. The root-mean-square (RMS) surface roughness was calculated as the standard deviation of all the height values within an image area using Nanoscope Analysis_v1.40 image processing software. The scan rate was adjusted depending upon the sample and was lower than $1.2 \mathrm{~Hz}$.

\subsection{Statistical Analysis}

Differences between lens materials in unworn lens surface roughness (RMS) were tested using a two-sided two-sample t-test assuming unequal variances. Differences between lens materials in worn lens surface roughness (RMS) were tested using a two-sided paired t-test. Differences between worn and unworn lens surface roughness (RMS) for nesofilcon A were tested using a two-sided, two-sample t-test assuming unequal variances. Differences between worn and unworn lens surface roughness (RMS) for delefilcon A were tested using a two-sided, two-sample t-test. Differences between COF values were tested using exact two-sided Wilcoxon two-sample tests. Differences were deemed significant if $\mathrm{p}<0.05$.

\section{Results}

\subsection{Physical Changes in Lenses After Wear as Reflected by Changes in $\mathrm{COF}$}

Calculated COFs on lenses appear in Figure 2. Both static and kinetic COFs were greater on delefilcon $\mathrm{A}$ than on nesofilcon A under the same test conditions $(p<0.01$ for both comparisons). Static COF on nesofilcon A increased significantly after wear, from $0.04 \pm 0.02$ before to $0.14 \pm$ 0.07 after (Figure 2; mean \pm standard deviation, $\mathrm{p}<0.01$ ); kinetic COF trended higher after wear, from $0.05 \pm 0.02$ before to $0.06 \pm 0.02$ after, but the difference was not significant $(\mathrm{p}=0.14)$. Similarly, static COF on delefilcon A increased from $0.64 \pm 0.12$ before wear to $0.91 \pm 0.21$ after $(\mathrm{p}<0.01)$, while kinetic COF on delefilcon A trended higher after wear, from $0.12 \pm 0.02$ before to $0.13 \pm 0.02$ after, but the difference was not significant $(\mathrm{p}=0.18)$.

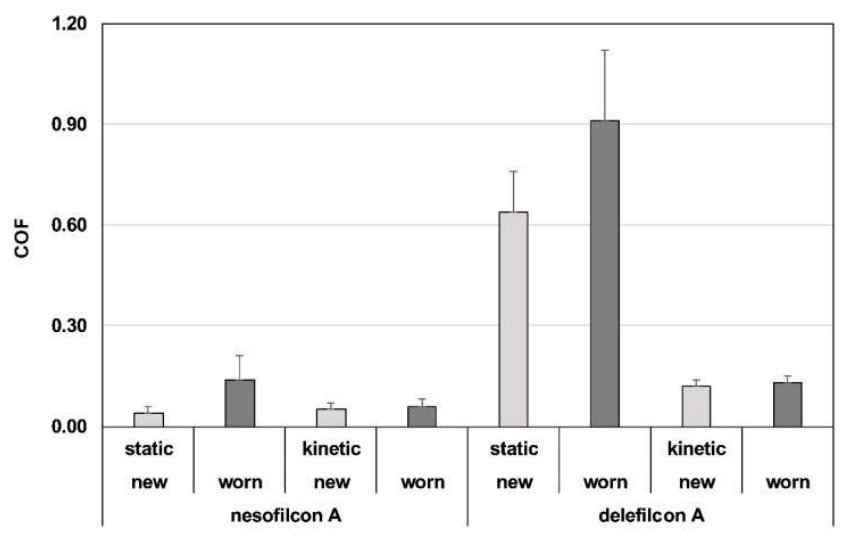

Figure 2. Static and kinetic coefficient of friction (COF) of lenses before and after 4 hours of wear. Light Grey Bar - unworn lens; Dark Grey Bar - worn lens.

\subsection{Morphological Changes in Lens Surfaces After Wear as Illustrated by AFM Imaging}

Representative topographic images of nesofilcon A, both out of the package and after 4 hours wear appear in Figure 3. Prior to wear, the nesofilcon A lens exhibited a relatively smooth surface lacking distinct features (Figure 3A). After wear, a relatively sparse lens deposit was evident 
(topographic image, Figure 3B), with disperse, $\mu \mathrm{m}$-scale material scattered over the surface (phase image, Figure 3C). The topographic image (Figure 3B) illustrates surface topography after wear of the lens, while the phase image (Figure 3C) illustrates areas of the lens where deposits differing in stiffness from the lens material are adhered. The mean RMS surface roughness of the lens increased from 1.9 $\pm 0.2 \mathrm{~nm}$ to $7.2 \pm 3.7 \mathrm{~nm}$ after wear $(\mathrm{p}=0.047$; Figure 4$)$, as seen in the $3 \mathrm{D}$ image of the lens (Figure 3D).
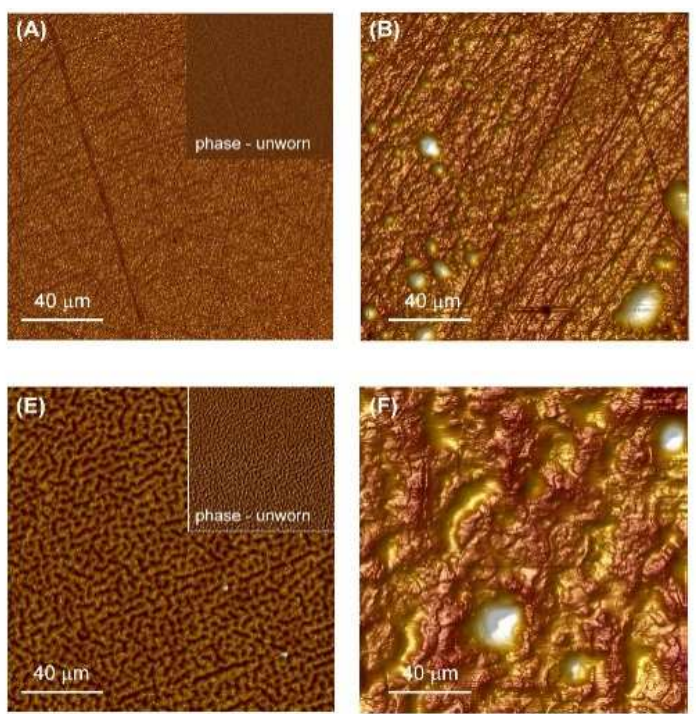

(D)
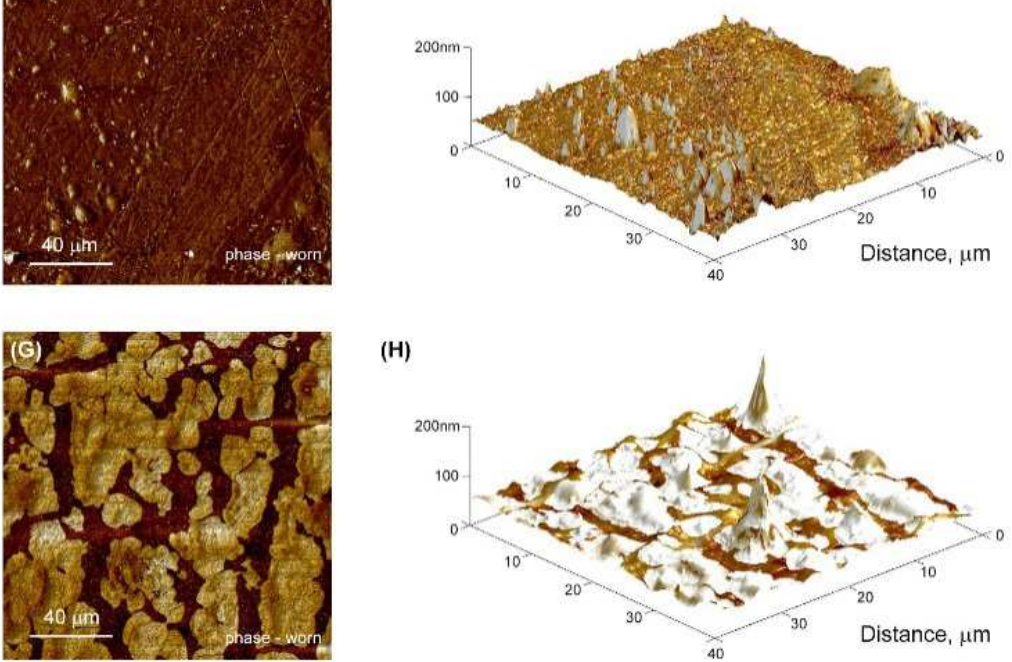

(H)

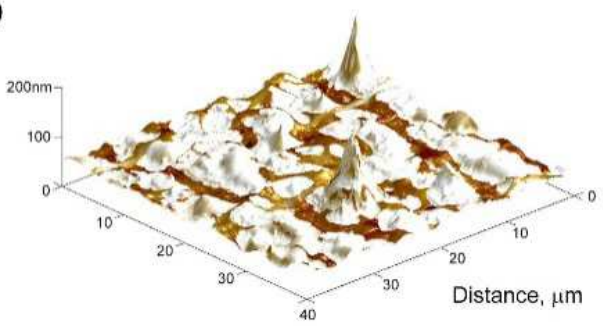

Figure 3. AFM topographic and phase images of A. unworn nesofilcon A lens; B. topographic and C. phase images of worn nesofilcon A lens; D. $3 D$ topographic image with localized phase image of worn nesofilcon A lens. E. unworn delefilcon A lens; F. topographic and G. phase images of worn delefilcon A lens; H. 3D topographic image with localized phase image of worn delefilcon A lens.

Analogous representative images of delefilcon A lenses appear in Figures 3E-H. Prior to wear, the delefilcon A lens exhibited a branched, cobblestone-patterned surface morphology (Figure 3E). After wear, this branched morphology was no longer visible, and semi-contiguous, globular, near-confluent lens deposits were observed as islands covering the majority of the lens surface (topographic, Figure 3F; phase, Figure 3G). The mean RMS surface roughness of the lens trended lower from $14.2 \pm 5.5$ $\mathrm{nm}$ down to $10.9 \pm 4.0 \mathrm{~nm}$ after wear $(\mathrm{p}=0.30$; Figure 4$)$, as seen in the 3D image of the lens (Figure 3H). RMS roughness of the nesofilcon $A$ lens was less than that of delefilcon A lens before wear $(p<0.01)$ and trended lower after wear, but the difference was not significant after wear $(\mathrm{p}=0.17)$; delefilcon A topography was quite different before (Figure 3E) and after (Figures $3 \mathrm{~F}$ and $3 \mathrm{G}$ ) wear.

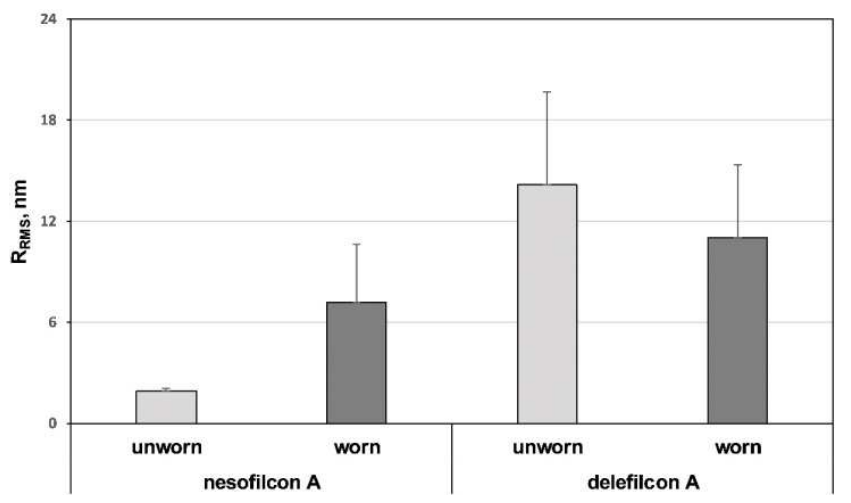

Figure 4. RMS surface roughness of unworn and worn lenses. Light Grey Bar-unworn lens; Dark Grey Bar - worn lens.

\section{Discussion}

\subsection{Blinking and Lens Friction}

Blinking is essential for maintaining a functioning tear film, which is necessary for a healthy ocular surface and clear vision. Using a high-speed camera, Kwon et al. characterized the blink cycle as having four distinct phases: closing, closed, early opening and late opening [25]. They found that the upper eyelid accelerates, reaches maximum speed, then decelerates during both eye closing and opening. As the upper eyelid begins to move during closure, it first encounters static frictional resistance. As the closing phase proceeds, it encounters kinetic frictional resistance proportional to eyelid speed. As the opening phase begins, it again encounters static frictional resistance, then slow kinetic frictional resistance also proportional to eyelid speed as opening progresses.

During contact lens wear, maintenance of a smooth, durable lens surface helps spread the tear film, reduce friction, and preserve optics. Assuming a nominal blink rate of 20 blinks per minute [26], and 16 waking hours per day, an average person blinks over nineteen-thousand times daily, wiping the lens and re-establishing the tear film with each pass of the eyelid. Lens deposits that occur during wear are problematic both for comfort due to the roughened surface [3], and for vision due to changes in lens geometry and light refraction [27]. Deposits can manifest as increased friction between the lens and the eyelid during the blink cycle. Lens friction may be clinically relevant as COF on both PHEMAbased and silicone hydrogels is reported to correlate with 
subjective lens comfort [1-3].

\subsection{Lens Surface Morphology and Friction}

In this study, frictional forces were measured on nesofilcon A and delefilcon A contact lenses at the applied pressure and sliding speeds experienced by a contact lens on the human eye during closure. Worn lenses show increased friction or a trend towards increased friction (both static and kinetic), compared with values measured on unworn lenses for both lens models. Static COF (friction at the initiation of movement) was significantly greater on the delefilcon A lens compared with the nesofilcon A lens, both before and after 4 hours of wear (Figure 2). Similarly, Kinetic COF (friction measured at constant force and rotation) was significantly greater on the delefilcon A lens compared with the nesofilcon A lens, both before and after 4 hours of wear.

Although surface water loss from delefilcon A but not nesofilcon A lenses was reported previously [28], the effect of water loss upon surface morphology of the lenses has not been reported. Therefore, lenses were imaged by AFM before and after wear to determine if changes in COF could be explained by physical phenomena, e.g., changes in polymer morphology or lens deposits. Both of the lenses evaluated in this study demonstrated altered surface characteristics after wear. AFM images show that the unworn nesofilcon A lens surface is more uniform and smoother than is the unworn delefilcon A lens, as indicated by lower RMS surface roughness before wear (Figures 3B-D versus 3F-H, and 4). While small, disperse deposits on nesofilcon A were sparse in coverage, relatively larger, heterogenous deposits were dense in coverage on the delefilcon A lens. Although two distinct deposit morphologies are evident on the worn delefilcon A lens (compare lighter and darker areas in Figures $3 \mathrm{G}$ and $3 \mathrm{H}$ ), neither matches that of the pre-wear polymer substrate (Figure 3E). It is notable that the roughness of the delefilcon A surface trends lower after wear. This suggests that biological deposit adherent to the lens after its hydrophilic surface has collapsed is smoother than the lens polymer itself.

Comparison of COF and RMS surface roughness measured before and after lens wear fails to find an exact correlation between the two. RMS surface roughness of nesofilcon A increased from $1.9 \pm 0.2 \mathrm{~nm}$ before wear to 7.2 $\pm 3.7 \mathrm{~nm}$ after due to sorbed biological components, which resulted in increased static COF from $0.04 \pm 0.02$ to $0.14 \pm$ 0.07 but no significant change in kinetic COF $(0.05 \pm 0.02$ before versus $0.06 \pm 0.02$ after). In contrast, roughness of the delefilcon A lens trended lower after wear, from $14.2 \pm 5.5$ $\mathrm{nm}$ down to $10.9 \pm 4.0 \mathrm{~nm}$, while static COF increased, from $0.64 \pm 0.12$ to $0.91 \pm 0.21$, and kinetic COF trended higher, from $0.12 \pm 0.02$ to $0.13 \pm 0.02$, but was not statistically significantly different. AFM images illustrating deposition of tear film lipids and/or proteins during wear appear to show increased roughness of both nesofilcon $\mathrm{A}$ and the delefilcon A surfaces after wear, but numerical analysis of the images finds that the RMS roughness of biological deposits on the delefilcon A surface was less than that of the underlying polymer. While changes in COF may be related to surface roughness, the character of the deposits relative to the underlying polymer also affect frictional forces, and surface roughness alone could not predict $\mathrm{COF}$ on these two materials.

\subsection{Circumferential COF Measurement Method Versus Other (Axial) Methods}

The COF measurement approach described here is novel. Sample mounting and friction measurement may be performed in $15 \mathrm{~min}$. The method differs from many others in that it measures COF during circumferential rather than lateral motion of the probe, which may improve measurement repeatability.

Comparison of COF values measured in this study to those measured in different studies using a different measuring approach and experimental system is difficult, and little data are published on the two lenses evaluated in this study. However, such comparisons may be useful for identifying general trends and wear phenomena. For example, a COF of $0.02 \pm 0.05$ on delefilcon A measured using a non-traditional measurement system was reported (with no data for comparative lenses) [29]. Dunn et al. similarly reported average delefilcon A COF measured with a sliding borosilicate glass probe and BBS as the lubricating fluid of $0.018 \pm 0.006$ below normal forces of 1,000 $\mu \mathrm{N}$ and $0.022 \pm 0.007$ at higher loads [30]. Further, they reported that the surface hydrogel of delefilcon A collapsed at higher contact pressures, resulting in stick-slip and static COF greater than 0.5 , consistent with an initial COF of $0.64 \pm 0.12$ measured in this study. In contrast, Mann and Tighe measured COFs out of the package of $0.011 \pm 0.008$ versus $0.056 \pm 0.013$ for delefilcon A and nesofilcon A, respectively using a different test system and operating parameters [31]. The lower value for delefilcon A suggests that the surface remained intact under the test conditions used, while in our study the surface collapsed.

Reported surface refractive index measurements indicating that the surface water content of the delefilcon A lens drops from in excess of $80 \%$ down to $33 \%$ after fifteen minutes of wear suggest that the surface also collapses on eye at normal eyelid pressure where tear fluid is the lubricant [28]. Based upon transmission electron microscopy (TEM) images, the hydrophilic surface collapses down to a thickness of $1.5 \mu \mathrm{m}$ when dehydrated in vitro (unpublished data).

Dunn et al. noted that a rigid probe (such as the stainless steel probe used in the present study and many others) may not reproduce physiological lubrication of two soft, hydrated articulating surfaces such as with eyelid and lens and instead propose hydrogel probes for more relevant COF measurement [32]. However, rigid probes are more easily and repeatably fabricated, easily cleaned, and much more durable; repeatable measurements with hydrogel probes would be quite challenging. While the goal of rapid and repeatable measurement in this study was achieved and was consistent with physical observations, the clinical relevance of the method used in this study and all other COF measurement methods remains to be definitively demonstrated.

COFs of other lenses using the experimental approach and 
measurement system of this study have also been reported. In one preliminary study, static COF on balafilcon A $(1.1 \pm$ $0.09)$ was greater than that on delefilcon $\mathrm{A}(0.63 \pm 0.09)$, which were both greater than on samfilcon $\mathrm{A}(0.03 \pm 0.01)$, senofilcon A $(0.05 \pm 0.01)$, and comfilcon A $(0.01 \pm 0.01)$ [33]. The former result is directionally consistent with reported five-fold greater $\mathrm{COF}$ on balafilcon $\mathrm{A}$ relative to delefilcon A, measured using a sliding probe [34]. In another preliminary study, static COF on delefilcon A $(0.63 \pm 0.12)$ and nelfilcon $\mathrm{A}(1.44 \pm 0.40)$ were greater than on nesofilcon A $(0.04 \pm 0.02)$, narafilcon A $(0.03 \pm 0.00)$, etafilcon $(0.06 \pm$ $0.01)$, and omafilcon A $(0.16 \pm 0.06)$ [35]. While the consistency of these results is encouraging, a properly designed experiment using more lenses, as well as corroborating clinical study are required to validate the method. Also, as Dunn et al. note [32], the operating parameters that best support clinical observation remain to be established (using this or any other method).

\subsection{Character of Lens Deposits}

AFM images reveal the physical nature of lens deposits but do not identify the specific chemical and biological species adhered on the lens. While definitive identification of lens deposits is beyond the scope of this study, the presence of ionic polyamidoamine and poly (acrylamide-acrylic acid)-derived polymers at the delefilcon A lens surface suggests that the deposit on delefilcon A may be dominated by lysozyme, which has been identified as the tear protein most affecting lens comfort [36], particularly in denatured form [37]. Adsorption of lysozyme on lenses fabricated of non-ionic HEMA and ionic methacrylic acid (MAA) monomers was reported to be thirtyfold greater than on those fabricated of PHEMA alone [38]. In one related study, lens polymers fabricated with 5\% MAA monomer increased lysozyme sorption 200X, while those fabricated with $10 \%$ non-ionic monomer (NVP) did not affect sorption [39]. In another related study, lysozyme sorption on ionic etafilcon A and ionic vifilcon A lenses was thirty-fold and ten-fold greater, respectively than on non-ionic tefilcon A lenses [40]. Additional studies report extensive sorption of lysozyme on ionic lenses [41], and that the majority of lysozyme deposited on high water, ionic FDA Group IV lenses [19] retains its activity once sorbed $[36,37]$. While the AFM images (Figures 3F-H) suggest denatured surface deposits on worn delefilcon A lenses, further studies are warranted to confirm a lysozyme-rich deposit, and whether or not sorbed lysozyme is active or denatured. In the absence of such studies, it remains possible, although unlikely, that the apparent deposit is polymeric rather than biological in nature, i.e., the polymeric surface of delefilcon A rearranges or degrades on eye.

AFM used previously to characterize the surfaces of various contact lenses (primarily silicone hydrogels) before and after wear is reported in literature. González-Méijome et al. reported lens-dependent increases in RMS surface roughness of silicone hydrogels with wear (balafilcon A, from $15.2 \pm 3.81$ to $18.8 \pm 2.56 \mathrm{~nm}$; lotrafilcon $\mathrm{A}$, from 4.98 \pm 0.60 to $17.7 \pm 1.98 \mathrm{~nm}$; lotrafilcon $\mathrm{B}$, from $5.27 \pm 1.31$ to $11.6 \pm 4.91 \mathrm{~nm}$; galyfilcon $\mathrm{A}$, from $3.68 \pm 2.61$ to $17.8 \pm 2.43$ $\mathrm{nm}$; comfilcon A, from $3.62 \pm 2.39$ to $6.89 \pm 5.42 \mathrm{~nm}$ ) [42]. Lira et al. similarly reported increased RMS surface roughness with wear (balafilcon A from $9.5 \pm 0.7$ to $23.7 \pm$ $15.2 \mathrm{~nm}$; lotrafilcon B from $5.7 \pm 2.8$ to $7.3 \pm 5.5 \mathrm{~nm}$; galyfilcon A from $3.04 \pm 0.1$ to $40.0 \pm 17.3 \mathrm{~nm}$ ) [12]. Thus, delefilcon A roughness measurements from the current study (14.2 nm unworn and $10.9 \mathrm{~nm}$ worn) fall within the range reported for other silicone hydrogel lenses (3.04-15.2 nm unworn and 6.89-40.0 nm worn).

\section{Conclusions}

A COF measurement method that allowed for rapid sample mounting and analysis was successfully developed. Both static and kinetic COF measured on unworn nesofilcon A lenses were lower that than those measured on unworn delefilcon A lenses. The relatively high static COF measured on delefilcon A likely indicates that its hydrophilic surface collapsed during the test. Both lenses attracted lipid/protein over four hours of wear, but deposits were sparse on the former and near-confluent on the latter in AFM images. The branched, hydrophilic surface of unworn delefilcon A appeared collapsed on worn lenses. Static COF on nesofilcon A increased after wear due to biological deposit, and kinetic COF trended higher after wear but was not significantly different, consistent with the physical changes observed by AFM. Similarly, static COF on delefilcon A increased and kinetic COF trended higher after wear but was not significantly different. We were unable to establish a hard correlation between RMS surface roughness calculated from AFM images and COF, suggesting that surface roughness alone is insufficient to predict COF. While clinical validation of the COF test method remains incomplete, the method may prove useful for new contact lens development.

\section{Acknowledgements}

The abstract of this paper was presented at the Annual Meeting of the Association for Research in Vision and Ophthalmology (ARVO) held at Orlando, FL USA on May 3-8, 2014 as a poster presentation (program number 6067) with interim findings. The poster's abstract was published online and is available for download at http://iovs.arvojournals.org/article.aspx? articleid=2271731.

\section{Disclosure}

Authors Hook, Schafer, Steffen, Wygladacz, Reindel, and Mosehauer are direct employees of Bausch \& Lomb Incorporated. Author Lusignan was an employee of Bausch $\&$ Lomb Incorporated at the time of the study.

\section{References}

[1] Roba M, Duncan EG, Hill GA, Spencer ND, Tosatti SGP. Friction measurements on contact lenses in their operating environment. Tribol Lett. 2011; 44 (3): 387-397. 
[2] Brennan N. Contact lens-based correlates of soft lens wearing comfort. Optom Vis Sci. 2009; 86: E-abstract 90957. Available from: https://www.aaopt.org/detail/knowledgebase-article/contact-lens-based-correlates-soft-lens-wearingcomfort. Accessed October 15, 2019.

[3] Stapleton F, Tan J. Impact of contact lens material, design, and fitting on discomfort. Eye Contact Lens. 2017; 43 (1): 32-39.

[4] Nairn JA, Jiang T. Measurement of the friction and lubricity properties of contact lenses. Proceedings of ANTEC'95, Boston MA, May 7-11, 1995. Available from: http://www.cof.orst.edu/cof/wse/faculty/Nairn/papers/contacts .pdf. Accessed October 15, 2019.

[5] Rennie AC, Dickrell PL, Sawyer WG. Friction coefficient of soft contact lenses: measurements and modeling. Tribol Lett. 2005; 18 (4): 499-504.

[6] Sterner O, Aeschlimann R, Zürcher S, Scales C, Riederer D, Spencer ND, Tosatti SGP. Tribological classification of contact lenses: From coefficient of friction to sliding work. Tribol Lett. 2016; 63: 9.

[7] Dunn AC, Cobb JA, Kantzios AN, Lee SJ, Sarntinoranont M, Tran-Son-Tay R, Sawyer WG. Friction coefficient measurement of hydrogel materials on living epithelial cells. Tribol Lett. 2008; 30: 13-19.

[8] Ngai V, Medley JB, Jones L, Forrest J, Teichroeb J. Friction of contact lenses: silicone hydrogel versus conventional hydrogel. Tribol Interface Eng Ser. 2005; 48: 371-379.

[9] Sterner O, Aeschlimann R, Zürcher S, Osborn Lorenz K, Kakkassery J, Spencer ND, Tosatti SG. Friction measurements on contact lenses in a physiologically relevant environment: Effect of testing conditions on friction. Invest Ophthalmol Vis Sci. 2016; 57 (13): 5383-5392.

[10] Zhou B, Li Y, Randall NX, Li L. A study of the frictional properties of senofilcon-A contact lenses. [J]. Mech Behav Biomed Mater. 2011; 4 (7): 1336-42.

[11] Hagedorn S, Drolle E, Lorentz H, Srinivasan S, Leonenko Z, Jones L. Atomic force microscopy and Langmuir-Blodgett monolayer technique to assess contact lens deposits and human meibum extracts. [J]. Optom. 2015; 8 (3): 187-99.

[12] Lira M, Santos L, Azeredo J, Yebra-Pimentel E, Real Oliveira ME. Comparative study of silicone-hydrogel contact lenses surfaces before and after wear using atomic force microscopy. [J]. Biomed Mater Res B Appl Biomater. 2008; 85 (2): 361-7.

[13] Teichroeb JH, Forrest JA, Ngai V, Martin JW, Jones L, Medley J. Imaging protein deposits on contact lens materials. Optom Vis Sci. 2008; 85 (2): 1151-64.

[14] Toca-Herrera JL. Atomic force microscopy meets biophysics, bioengineering, chemistry, and materials science. ChemSusChem. 2019; 12 (3): 603-611.

[15] Maver U, Velnar T, Gaberšček C, Planinšek O, Finšgar M. Recent progressive use of atomic force microscopy in biomedical applications. TrAC Trends in Analytical Chemistr. 2016; 80: 96-111.

[16] Ye Z, Zhao X. Phase imaging atomic force microscopy in the characterization of biomaterials. [J]. Microsc. 2010; 238 (1): 27-35.

[17] FDA 510 (k) Summary K113703. Bausch +Lomb nesofilcon A contact lens. June 5, 2012. Available from: https://www.accessdata.fda.gov/cdrh docs/pdf11/K113703.pd f. Accessed October 15, 2019.

[18] FDA 510 (k) Summary K113168. Delefilcon A Soft Contact Lenses, 510 (k) Summary of Safety and Substantial Equivalence. March 30, 2012. Available from: https://www.accessdata.fda.gov/cdrh_docs/pdf11/K113168.pd f. Accessed October 15, 2019.

[19] Fda. gov [homepage on the Internet]. Rockville, MD: US Food and Drug Administration. [updated 2016 June 27; cited Aug 10, 2018]. FDA Executive Summary. Prepared for the May 13, 2014 Meeting of the Ophthalmic Devices Panel of the Medical Devices Advisory Committee. Contact Lens and Care Product Guidance Documents. Available from: https://creativesrv.bid/library/?sid=rwHURXwhuRGCIH8tyL 42nQm1kWWMxinLqASe2IMP0MombfhRhGJek51jW516oX PoLIJBAczaplY4npMyhoIHGcC5Bj1G8dBbNf3v\&fn=FDA $\% 20$ Executive $\% 20$ Summary $\% 20$ Prepared $\% 20$ for $\% 20$ the $\% 20$ May\%2013， \%202014\%20Meeting\%20of.pdf. Accessed October 15, 2019.

[20] Qiu Y, Samuel NT, Pruitt JD, et al., inventors; Novartis AG, assignee. Silicone hydrogel lens with a crosslinked hydrophilic coating. United States patent US 8529057. September 10, 2013. Available from: http://www.freepatentsonline.com/8529057.pdf. Accessed October 15, 2019.

[21] Pruitt J, Qiu Y, Thekveli S, Hart R. Surface characterisation of a water gradient silicone hydrogel contact lens (delefilcon A). Invest Ophthalmol Vis Sci. 2012; 53: E-Abstract 6107. Available from: https://iovs.arvojournals.org/article.aspx?articleid=2359806. Accessed October 15, 2019.

[22] Shaw AJ, Collins MJ, Davis BA, Carney LG. Eyelid pressure and contact with the ocular surface. Invest Ophthalmol Vis Sci. 2010; 51 (4): 1911-7.

[23] Kovalev AE, Dening K, Persson BN, Gorb SN. Surface topography and contact mechanics of dry and wet human skin. Beilstein J Nanotechnol. 2014; 5: 1341-8.

[24] Mourougou-Candoni N. Chapter 3. Tapping mode AFM imaging for functionalized surfaces. In: Atomic Force Microscopy Investigations into Biology - From Cell to Protein (C Frewin, Ed.). London: Intech Open Limited; 2012: 55-84.

[25] Kwon KA, Shipley RJ, Edirisinghe M, Ezra DG, Rose G, Best SM, Cameron RE. High-speed camera characterization of voluntary eye blinking kinematics. [J]. R Soc Interface 2013; 10 (85): 20130227.

[26] Abusharha AA. Changes in blink rate and ocular symptoms during different reading tasks. Clin Optom (Auckl). 2017; 9: 133-138.

[27] Gellatly KW, Brennan NA, Efron N. Visual decrement with deposit accumulation of HEMA contact lenses. Am J Optom Physiol Opt. 1988; 65 (12): 937-41.

[28] Schafer J, Steffen R, Reindel W, Chinn J. Evaluation of surface water characteristics of novel daily disposable contact lens materials, using refractive index shifts after wear. Clin Ophthalmol. 2015; 9: 1973-9.

[29] Sawyer W, Urueña J, Angelini T, Dunn A, Pruitt J. Laboratory model for wear of contact lenses and effects on lens lubricity of surface gel layers. Invest Ophthalmol Vis Sci. 2013; 54: EAbstract 493. Available from: https://iovs.arvojournals.org/article. aspx?articleid=2149842. Accessed October 15, 2019. 
[30] Dunn AC, Juan Manuel Urueña MJ, Huo Y, Perry SS, Angelini TE, Sawyer WG. Lubricity of surface hydrogel layers. Tribol Lett. 2013; 49 (2): 371-378.

[31] Mann A, Tighe BJ. Chapter 3. Ocular biotribology and the contact lens: Surface interactions and ocular response. In: Biomaterials and Regenerative Medicine in Ophthalmology (Second Edition). London: Elsevier. Woodhead Publishing Series in Biomaterials; 2016: 45-74.

[32] Dunn AC, Sawyer WG, Angelini TE. Gemini interfaces in aqueous lubrication with hydrogels. Tribol Lett. 2014; 54 (1): 59-66.

[33] Hook D, Taft S, Steffen R, Merchea MM. Comparing the static and kinetic friction of unworn and worn silicone hydrogel contact lenses. Invest Ophthalmol Vis Sci. 2014; 55: E-Abstract 4654. Available from: https://iovs.arvojournals.org/article.aspx? articleid=2270186. Accessed October 15, 2019.

[34] Rudy A, Huo Y, Perry SS, Ketelson HA. Surface mechanical and tribological properties of silicone hydrogels measured by Atomic Force Microscopy. Invest Ophthalmol Vis Sci. 2012; 53: E-Abstract 6114. Available from: https://iovs.arvojournals.org/article.aspx? articleid=2359813. Accessed October 15, 2019.

[35] Schafer J, Hook D, Lusignan C, Steffen RB. Coefficient of friction analysis of unworn and worn daily disposable contact lenses. Invest Ophthalmol Vis Sci. 2015; 56: E-Abstract 6110. Available from: https://iovs.arvojournals.org/article.aspx?articleid=2336216. Accessed October 15, 2019.
[36] Subbaraman LN, Glasier MA, Varikooty J, Srinivasan S, Jones L. Protein deposition and clinical symptoms in daily wear of etafilcon lenses. Optom Vis Sci. 2012; 89 (10): 14509.

[37] Suwala M, Glasier MA, Subbaraman LN, Jones L. Quantity and conformation of lysozyme deposited on conventional and silicone hydrogel contact lens materials using an in vitro model. Eye Contact Lens. 2007; 33 (3): 138-43.

[38] Castillo EJ, Koenig JL, Anderson JM, Lo J. Protein adsorption on hydrogels. II. Reversible and irreversible interactions between lysozyme and soft contact lens surfaces. Biomaterials. 1985; 6 (5): 338-45.

[39] Garrett Q, Laycock B, Garrett RW. Hydrogel lens monomer constituents modulate protein sorption. Invest Ophthalmol Vis Sci. 2000; 41 (7): 1687-95.

[40] Garrett Q, Garrett RW, Milthorpe BK. Lysozyme sorption in hydrogel contact lenses. Invest Ophthalmol Vis Sci. 1999; 40 (5): 897-903.

[41] Garrett Q, Chatelier RC, Griesser HJ, Milthorpe BK. Effect of charged groups on the adsorption and penetration of proteins onto and into carboxymethylated poly (HEMA) hydrogels. Biomaterials. 1998; 19 (23): 2175-86.

[42] González-Méijome JM, López-Alemany A, Almeida JB, Parafita MA. Surface AFM microscopy of unworn and worn samples of silicone hydrogel contact lenses. [J]. Biomed Mater Res B Appl Biomater. 2009; 88 (1): 75-82. 